\title{
Effect of Helicobacter pylori infection on intragastric urea and ammonium concentrations in patients with chronic renal failure
}

\author{
W D Neithercut, P A Rowe, A M El Nujumi, S Dahill, K E L McColl
}

\begin{abstract}
Aim-To assess the value of measuring the gastric juice urea : ammonium ratio in detecting Helicobacter pylori infection in patients with chronic renal failure.

Methods-Twenty three (12 men) patients with established chronic renal failure and dyspepsia were studied. Gastric juice $(2 \mathrm{ml})$ was aspirated during endoscopy to measure urea and ammonium. The upper gastrointestinal tract was routinely inspected and two antral biopsy specimens obtained. The ${ }^{14} \mathrm{C}$-urea breath test was conducted within 14 days of endoscopic examination to determine $H$ pylori antibody response.
\end{abstract}

Results-The median (range) serum urea concentration in 11 patients with renal failure and $H$ pylori infection was similar to that in 12 without $H$ pylori infection. The median gastric juice urea concentration in subjects with infection was lower than that in the subjects without infection $(p<0.01)$. The median gastric juice ammonium concentration in subjects with the infection was higher compared with subjects without infection $(p<0 \cdot 01)$. There was an overlap of the urea and ammonium concentrations in gastric juice from both $H$ pylori positive and negative subjects. The urea : ammonium ratio was $0.16(0 \cdot 01-1 \cdot 11)$ for subjects with $H$ pylori compared with 1.63 $(1 \cdot 0-18 \cdot 9)$ in subjects without infection (p $<0.001$ ).

Conclusion-The urea : ammonium ratio differentiated both groups, with the exception of one false negative result. The urea : ammonium ratio proved almost as effective in identifying the presence of $H$ pylori infection in subjects with chronic renal failure as it had in subjects with normal renal function.

(F Clin Pathol 1993;46:544-547)

Infection of the gastric antral mucosa with Helicobacter pylori occurs in $40 \%$ of the adult population $^{1}$ and in more than $95 \%$ of patients with duodenal ulcer disease. ${ }^{2}{ }^{3}$ Eradication of this infection significantly reduces rate of relapse of duodenal ulcer $^{3}$ and may also improve non-ulcer dyspepsia. ${ }^{4}$ The ability to detect infection with this organism and to confirm its eradication is therefore likely to become increasingly important in the management of upper gastrointestinal disease.
$H$ pylori is remarkable for its high urease activity and this property has been used clinically to detect the presence of infection. The rapid urease test detects the presence of $H$ pylori infection by the change in colour of a $\mathrm{pH}$ sensitive gel as a result of the bacterium's urease activity. ${ }^{5}$ The ${ }^{14} \mathrm{C}$-urea breath test detects the presence of $H$ pylori infection by the production of ${ }^{14} \mathrm{C}-\mathrm{CO}_{2}$ in the breath as a result of the hydrolysis of ${ }^{14} \mathrm{C}$-urea from the bacterium's urease activity. ${ }^{6}$ In an earlier study we discovered that the ratio of the urea to ammonium concentration in gastric juice samples from subjects with normal renal function could also be used to detect the presence of infection by $H$ pylori as accurately as the ${ }^{14} \mathrm{C}$-urea breath test. ${ }^{7}$

Clinicians disagree about the concentrations of urea and ammonium present in gastric juice samples from subjects with or without $H$ pylori infection. Our earlier study showed that median gastric juice urea concentrations of $0.8 \mathrm{mmol} / 1$ in the presence of infection rose to $2 \cdot 1 \mathrm{mmol} / 1$ when $H$ pylori was eradicated. These findings were similar to those of Marshall and colleagues, who reported mean urea concentrations of 0.45 $\mathrm{mmol} / \mathrm{l}$ in the presence of infection and a similar rise following eradication. ${ }^{8}$ Higher mean gastric urea concentrations of 4.3 and $3 \cdot 7$ $\mathrm{mmol} / \mathrm{l}$ were found in subjects with this infection in two other studies. ${ }^{910}$ After infection had been eradicated these two other groups found no change in the urea concentration.

Marshall reported mean gastric juice ammonium concentrations of $34 \mathrm{mmol} / \mathrm{l}$ when infection was present ${ }^{8}$ compared with $3.4 \mathrm{mmol} / 1$ in our previous study ${ }^{7}$ and 3.7 $\mathrm{mmol} / \mathrm{l}$ found by another group. ${ }^{9}$ The mean gastric juice ammonium concentrations reported in the absence of infection ranged from undetectable values to $11 \cdot 2 \mathrm{mmol} / \mathrm{l}^{7-10}$

We have already shown that the production of ammonium by $H$ pylori is usually limited by the availability of urea and that if urea is infused into gastric juice then this will result in increased gastric juice concentrations of ammonium. ${ }^{11}$ The concentration of urea in gastric juice is usually proportional to the serum urea concentration. Patients with chronic renal failure have higher gastric juice urea concentrations and this may also result in higher gastric juice ammonium concentrations. ${ }^{9}$

Methods

Twenty three patients (12 male) with estab- 
lished chronic renal failure and dyspeptic symptoms were investigated to examine the effect of chronic renal failure on the gastric juice urea and ammonium concentrations.

During endoscopy and just after entering the stomach, $2 \mathrm{ml}$ of gastric juice was aspirated through the suction channel of the endoscope and collected in a trap inserted in the suction line. Routine inspection of the upper gastrointestinal tract was then performed and two antral biopsy specimens were obtained. One specimen was fixed in formalin before being stained with Cresyl Fast Violet. The presence of $H$ pylori-like organisms was noted. Each subject also had a ${ }^{14} \mathrm{C}$-urea breath test. At the time of endoscopy blood samples were also obtained to determine urea and ammonium concentrations. The anticoagulated blood sample for ammonium concentration was centrifuged at $3000 \times g$ and $4^{\circ} \mathrm{C}$ for 10 minutes and the plasma frozen at $-20^{\circ} \mathrm{C}$ until analysis by an enzymatic method (Sigma Chemical Co. Dorset, England).

The gastric juice samples were stored frozen at $-20^{\circ} \mathrm{C}$ until analysis as a previous study had shown that gastric juice ammonium concentrations were stable at $-20^{\circ} \mathrm{C} .^{12}$ Before analysis the samples were centrifuged at $3000 \times g$ for 10 minutes to remove mucus. The concentration of ammonium was measured in the supernatant fluid following dilution in $0.2 \mathrm{~mol} / 1$ phosphate buffer $(\mathrm{pH}$ 7.4), using the enzymatic method (Sigma Chemical Co, Dorset, England) adapted for the Cobas Bio (Roche, Welwyn Garden City, Herts). ${ }^{12}$

Urea concentrations were measured using

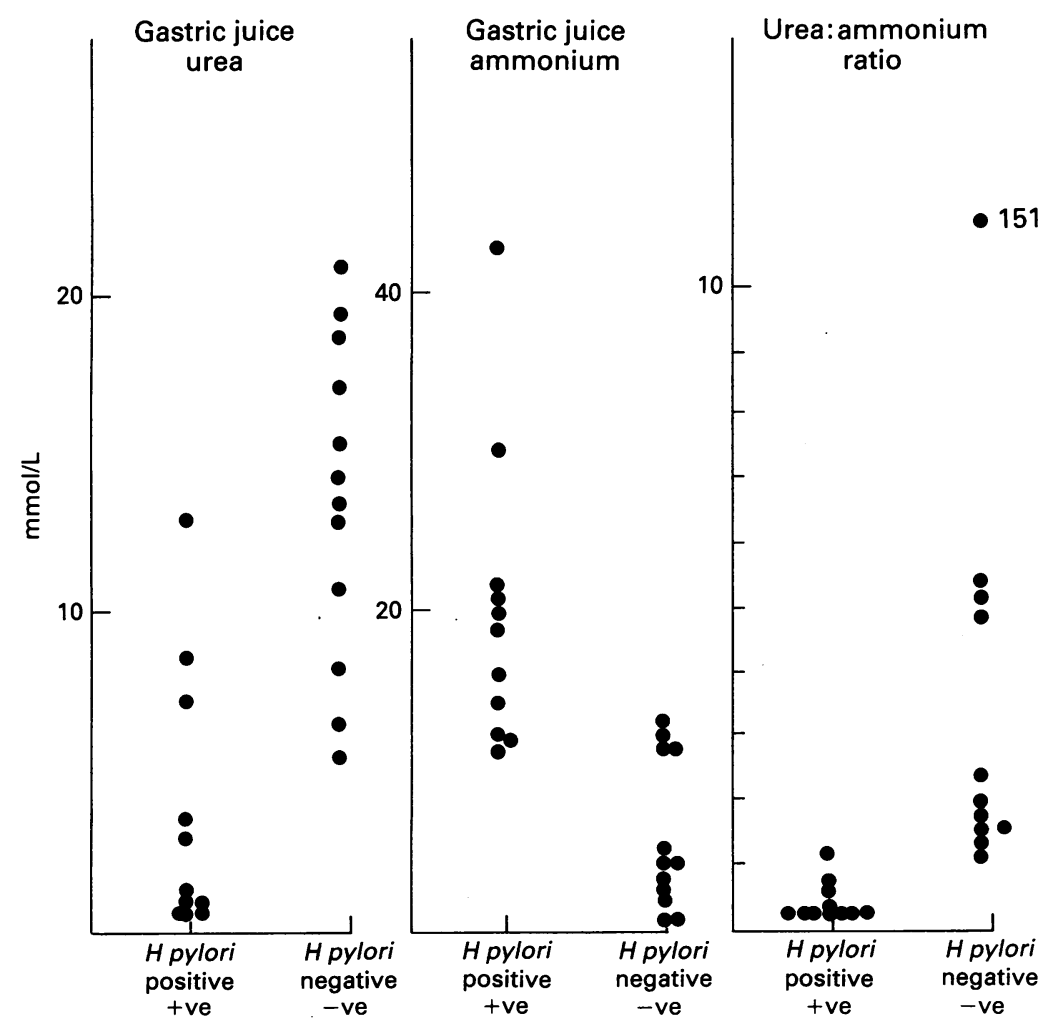

Gastric juice urea and ammonium concentrations and their ratio in subjects with chronic renal failure. an automated urease method (SMAC I, Bayer, Basingstoke). ${ }^{12}$ All samples were analysed without knowledge of the $H$ pylori antibody response of the individuals studied.

The ${ }^{14} \mathrm{C}$-urea breath tests were conducted within 14 days of endoscopic examination in the manner already described. The ${ }^{14} \mathrm{C}$-urea breath test is a reliable means of determining $H$ pylori infarction in subjects with chronic renal failure, ${ }^{13}$ provided that a higher upper limit of normal of $50 \mathrm{~kg} \%$ dose $/ \mathrm{mmol} \mathrm{CO}_{2}$ $\times 100$ is used.

The rank sum Wilcoxon test for unpaired samples was used to compare differences between groups. The study was approved by the ethical committee of the Western Infirmary and all patients gave informed consent.

\section{Results}

$H$ pylori like organisms were detected in antral biopsy specimens from 11 of the patients. In all of them the 20 minute breath test value was more than $50 \mathrm{~kg} \%$ dose $/ \mathrm{mmol}$ $\mathrm{CO}_{2} \times 100$ (median 240, range 61-384). In the 12 in whom the organism was not identified the 20 minute breath test values were all less than $50 \mathrm{~kg} \%$ dose $/ \mathrm{mmol} \mathrm{CO}_{2} \times 100$ (median 10, range $0 \cdot 1-27$ ).

The serum urea concentrations from all subjects were greater than the reference range $(2 \cdot 5-7.5 \mathrm{mmol} / \mathrm{l})$ for healthy subjects. The median (range) serum urea concentration in those with the infection was $18.3 \mathrm{mmol} / 1$ (12.0-31.0 $\mathrm{mmol} / \mathrm{l})$ compared with $24 \cdot 0$ $\mathrm{mmol} / \mathrm{l}(10 \cdot 7-32.2 \mathrm{mmol} / \mathrm{l})$ in patients without the infection ( $p>0.5 ; \mathrm{NS})$. The median plasma ammonium concentrations were also greater than the reference range (12-47 $\mu \mathrm{mol} / \mathrm{l})$. In those with $H$ pylori infection the median was $300 \mu \mathrm{mol} / 1(8-1200 \mu \mathrm{mol}) \mathrm{com}-$ pared with $140 \mu \mathrm{mol}(<8-860 \mu \mathrm{mol} / 1)$ when infection was absent.

The median (range) gastric juice urea concentration in those with the infection was $2 \cdot 7$ $\mathrm{mmol} / \mathrm{l}(0.5-12.8 \mathrm{mmol} / \mathrm{l})$ compared with $13.4 \mathrm{mmol} / \mathrm{l}(5.4-20.8 \mathrm{mmol} / \mathrm{l})$ in non-infected subjects $(p<0.001)$ (figure). The median (range) gastric juice ammonium concentration was $18.9 \mathrm{mmol}(11.3-43.0 \mathrm{mmol} / \mathrm{l})$ in those with the infection compared with 3.7 $\mathrm{mmol} / \mathrm{l}(0.5-12.3 \mathrm{mmol} / \mathrm{l})$ in those without $(\mathrm{p}$ $<0.001$ ) (figure). The median concentrations of urea and ammonium were different in the two groups of patients with renal failure, but there was an overlap between those with the infection and those in whom it was absent or had been eradicated.

When the urea : ammonium ratio was calculated, the median value for $H$ pylori positive subjects was $0 \cdot 16(0 \cdot 01-1 \cdot 11)$ compared with $1.63(1.0-151)$ for $H$ pylori negative subjects $(p<0.001)$. All subjects with infection with the exception of one (ratio $=1 \cdot 11$ ) had a urea : ammonium ratio of less than 0.80 , and all those in whom it had been eradicated or was not present had a ratio greater than 0.90 (figure). 


\section{Discussion}

$H$ pylori infection is most frequently diagnosed clinically from its urease activity. The ${ }^{14} \mathrm{C}$-urea breath test is reproducible and is a sensitive method of detecting infection of the antral mucosa with $H$ pylori. An earlier study of patients with duodenal ulcers indicated that the 20 minute breath test value was as effective in detecting the presence of infection as calculating the area under the 120 minutes of the breath test curve. ${ }^{7}$ The 20 minute breath test has also been shown to be reliable in patients with chronic renal failure. ${ }^{13}$

This study has again shown that the urease activity of the organism results in reduced gastric juice urea and increased gastric juice ammonium concentrations. It is interesting to compare the gastric juice urea and ammonium concentrations and their ratio in the subjects with renal failure in this study with those we reported before from subjects without renal failure.

The concentration of gastric juice ammonium, in samples from patients with chronic renal failure who were $H$ pylori negative, median $3.7 \mathrm{mmol} / 1(0.5-12.3 \mathrm{mmol} / 1)$, was greater than that previously found in $H$ pylori negative subjects with normal renal function, median $0.64 \mathrm{mmol} / 1 \quad(<0.03-1.4 \mathrm{mmol} / 1){ }^{7}$ The gastric juice ammonium concentrations from $H$ pylori negative subjects with chronic renal failure, median $3.7 \mathrm{mmol} / 1(0.5-12.3$ $\mathrm{mmol} / \mathrm{l}$ ), however, were similar to those found in samples from subjects who had normal renal function but were $H$ pylori positive, median $3.4 \mathrm{mmol} / 1 \quad\left(1.0-13.1 \quad \mathrm{mmol} / 1 .{ }^{7}\right.$ Differences in reports of ammonium concentration in patients without $H$ pylori infection could therefore be explained by the presence of chronic renal failure in some subjects.

The reason why gastric juice ammonium concentrations are higher in subjects with chronic renal failure is not known. One possibility is that overgrowth of the gastric mucosa by urease producing organisms other than $H$ pylori could account for this. Secondly, the median plasma ammonium concentration, $300 \mu \mathrm{mol} / 1$ (range $8-1200 \mu \mathrm{mol} / \mathrm{l}$ ) in the $H$ pylori positive subjects with chronic renal failure was greater than the top of the reference range $(47 \mu \mathrm{mol} / 1)$. The hepatic synthesis of urea from ammonium and bicarbonate is reduced by excessive production of $\mathrm{H}^{+}$ions or impaired excretion of $\mathrm{H}^{+}$ions to conserve bicarbonate. ${ }^{14}{ }^{15}$ This might explain the higher plasma ammonium concentrations in these subjects. The ammonium load presented to the liver would also be increased as a result of $H$ pylori urease activity. Increased circulating ammonium concentrations could therefore also explain the increased gastric juice ammonium concentrations: ammonia which diffused from the plasma in the gastric juice would be trapped there by the acid pH in the stomach.

The gastric juice urea concentrations in samples from subjects with chronic renal failure who had $H$ pylori infection, median 2.7 $\mathrm{mmol} / \mathrm{l}$ (range $0.5-12.8 \mathrm{mmol} / \mathrm{l}$ ), overlapped with those previously reported in subjects with normal renal function but who were $H$ pylori negative, median $2.1 \mathrm{mmol} / 1$ (1.0-3.7 $\mathrm{mmol} / \mathrm{l})$. Differences in previous reports of urea concentration in patients with $H$ pylori infection could therefore also be explained by the presence of chronic renal failure in some subjects.

The values of the urea:ammonium ratio found in subjects with chronic renal failure who had $H$ pylori infection, $0 \cdot 16(0 \cdot 01-1 \cdot 11)$ were similar to those previously found in subjects with normal renal function who had $H$ pylori infection, $0.26(0.04-0.7))^{7}$ The values of the ratio for subjects without $H$ pylori infection but chronic renal failure 1.63 $(1 \cdot 0-151)$ were also similar to those from subjects with normal renal function 3.4 $(1 \cdot 1-113)$. The same cutoff value of 0.9 could therefore be used despite the presence of renal failure.

There was one false negative result in this study from a subject who had a 20 minute breath test value of $834 \%$ dose $/ \mathrm{mmol} \mathrm{CO}_{2} \times$ $\mathrm{kg} \times 100$. The false negative value of the ratio was caused by a high gastric juice urea concentration in the presence of infection. The ratio could therefore not be used alone to detect $H$ pylori in subjects with chronic renal failure, but as current practice is to use two different methods of detecting the microorganism then the urea: ammonia ratio would therefore be suitable as a second test for the detection of $H$ pylori infection.

In conclusion, infection with the organism results in reduced gastric juice urea concentrations and raised ammonium concentrations. The concentration of ammonium in gastric juice depends on the availability of gastric juice urea. Both the gastric juice urea and ammonium concentrations were increased in chronic renal failure and therefore make the detection of infection by either single measurement unreliable. The urea: ammonium ratio was less affected by the presence of renal failure and therefore again proved more suitable for use as a second test in the detection of infection with $H$ pylori.

This study was supported by a grant from the Biomedical Research Committee from the Scottish Home and Health Department.

1 Graham DY, Malata HM, Evans DG, Evans DJ, Klein PD, Adam E. Epidemiology of Helicobacter pylori in an asymptomatic population in the United States. asymptomatic population in the
Gastroenterology 1991;100:1495-501.

2 Marshall BJ, McGechie DB, Rogers PA, Glancy RG. Pyloric campylobacter infection and gastroduodenal disease. Med f A A ust 1985;142:439-44.

3 Marshall BJ, Goodwin CS, Warren JR, Murray R, et al. Prospective double blind trial of duodenal ulcer relapse after eradication of Campylobacter pylori. Lancet 1988;ii:1437-42.

4 McCarthy C, Patchett S, Collins R, Beattie S, Keane C, O'Morain C. Long term effect of Helicobacter pylori eradication in non-ulcer dyspepsia. Gastroenterology 1991;100:A121.

5 Marshall BJ, Warren JR, Francis GJ, Langton SR, Goodwin CS, Blincow ED. Rapid urease test in the management of associated gastritis. Am $₹$ Gastroenterol management of asso

6 Marshall BJ, Surveyor I. Carbon 14 urea breath test for the diagnosis of Campylobacter pylori associated gastritis. F Nucleic Med 1988;29:11-6.

7 Neithercut WD, Milne A, Chittajallu RS, El Nujumi AM, McColl KEL. The detection of Helicobacter pylori infection of the gastric mucosa by measurement of gastric aspirate ammonium and urea concentrations. Gut
1991;32:973-6. 
8 Marshall BJ, Langton SR. Urea hydrolysis in patients with Campylobacter pyloridis infection. Lancet 1986;1 i: 965-6.

$9 \mathrm{Kim} \mathrm{H,} \mathrm{Park} \mathrm{C,} \mathrm{Jang} \mathrm{WI,} \mathrm{et} \mathrm{al.} \mathrm{The} \mathrm{gastric} \mathrm{juice} \mathrm{urea} \mathrm{and}$ ammonia levels in patients with Campylobacter pylori. Am ₹ Clin Pathol 1990;94:187-91.

10 Bornschein W, Baurefeind A, Heimann KL. UreaseSchnelltests bei Campylobacter pylori besledlung der Magenschleimhaut [A rapid urease test in Campylobacter pylori colonisation of the gastric mucosa]. Gastroenterol f 1989;49:54-8.

11 Chittajallu RS, Neithercut WD, MacDonald AMI, McColl KEL. The effect of increasing Helicobacter pylori ammonium production by urea infusion on plasma gastrin concentrations. Gut 1991;32:21-4.
12 Neithercut WD. The urease activity of Helicobacter pylori and duodenal ulcer disease. Glasgow: University of Glasgow, [MD Thesis] 1992:54-64.

13 Rowe PA, El-Nujumi AM, Williams C, Dahill S, Briggs JD, McColl KEL. The diagnosis of Helicobacter pylori infection in uraemic patients. Am $\mathcal{F}$ Kidney Dis 1992;20:574-9.

14 Oliver J, Koelz AM, Costello J, Bourke E. Acid-base induced alterations in glutamine metabolism and ureogenesis in perfused muscle and rat liver. Eur 7 Clin Invest 1977;7:445-9.

15 Haussinger D, Seis $H$, Gerok W. Functional hepatocyte heterogeneity in ammonia metabolism. The intercellular glutamine cycle. $\mathcal{F}$ Hepatol $1984 ; 1: 3-14$. 